\title{
A Study on the Coupled Model of Hydrothermal-Salt for Saturated Freezing Salinized Soil
}

\author{
Xudong Zhang, ${ }^{1}$ Qing Wang, ${ }^{1}$ Gang Wang, Wenhua Wang, \\ Huie Chen, ${ }^{1}$ and Zhongqiong Zhang ${ }^{3}$ \\ ${ }^{1}$ College of Construction Engineering, Jilin University, Changchun 130026, China \\ ${ }^{2}$ College of Civil Engineering, Changchun Institute of Technology, Changchun 130000, China \\ ${ }^{3}$ Northwest Institute of Eco-Environment and Resources, Chinese Academy of Sciences, Lanzhou 730000, China \\ Correspondence should be addressed to Qing Wang; wangqing@jlu.edu.cn
}

Received 15 November 2016; Revised 28 February 2017; Accepted 2 March 2017; Published 20 April 2017

Academic Editor: Michele Brun

Copyright (C) 2017 Xudong Zhang et al. This is an open access article distributed under the Creative Commons Attribution License, which permits unrestricted use, distribution, and reproduction in any medium, provided the original work is properly cited.

\begin{abstract}
Water and heat interact in the process of freezing for the saturated soil. And for the salinized soil, water, heat, and salt interact in the freezing process, because salinized soil has soluble salt. In this paper, a one-dimensional mathematical coupled model of hydraulic-thermal-salt is established. In the model, Darcy's law, law of conservation of energy, and law of conservation of mass are applied to derive the equations. Consider that a saturated salinized soil column is subjected to the condition of freezing to model the moisture migration and salt transport. Both experiment and numerical simulation under the same condition are developed in the soil column. Then the moisture content and salt content between simulation and experiment are compared. The result indicates that simulation matches well with the experiment data, and after 96 hours, the temperature distribution becomes stable, freezing front reaches a stable position, and a lot of unfrozen water has time to migrate. Besides, the excess salt precipitates when the concentration is greater than the solubility, and the precipitation is distributed discontinuously. These results can provide reference for engineering geology and environmental engineering in cold region and saline soil area.
\end{abstract}

\section{Introduction}

Soil in permafrost and seasonally frozen ground is typical multiphases system. For the freezing soil, water, heat, and mechanics always interact with each other. Under the temperature gradient, moisture can be migrated. And the moisture migration may affect the change of soil pores, such as the size of pores and the pore water press, which may cause frost heave and the damage to the infrastructure $[1,2]$, while for the salinized soil in cold region the soluble salt which is dissolved in the water would be transported during the water migration in the process of freezing, which can cause the secondary salinization $[3,4]$. Thus the freezing of salinized soil is a complex process, which is referred to as hydrothermal-salt (HTS) process. And the salinization is an important concern since it brings the damage to agriculture, such as agricultural production and the engineering construction including building erosion and salt expansion.
The research of salinized soil includes its basic properties, salinization mechanism and assessment, the mathematical coupled model, and salinization control and improvement, in which the investigation of the coupled model is a focus in study [5]. As for the coupled process of soil that related to the freezing condition, much attention has been paid to the frost heave and the interaction among moisture heat and stress. During the freezing process, water migrates towards the freezing part constantly under the soil-water potential and results in the dynamic variation of the thermal conductivity [4, 6]. Harlan [7] derived the coupled equations and established coupled model of water and heat by finite difference method, based on which the coupled models were developed. Besides, induced by the water migration and phase change, the structure of soil would be changed, which leads to frost heave and the stress redistribution. In return, the structure changes would affect the water migration. Thus the thermal-hydromechanical models are proposed to describe 
the interaction of water heat and stress during freezing. And previous researches consist of the capillary model $[8,9]$, segregation potential model, rigid ice model, semiempirical approaches [10], and thermodynamical model. Konrad and Morgenstern [11] firstly proposed segregation potential model and studied the amount of water migration and frost heave behavior; then O'Neill and Miller [12] studied interaction between water and heat, proposed the rigid ice model, and modeled the formation of ice lens. Based on the rigid model, many scholars [13] started to do researches to study the coupled model in order to investigate the characteristics of frost heave, water migration, and heat transfer; thus this model was used widely. Duquennoi et al. [14] and Fremond and Mikkola [15] firstly proposed the thermodynamical model; and by using this model, they studied the change of dynamic change of water and heat in the process of soil freezing. Inspired by the thermodynamical model, Nishimura et al. [16] explored the analogy of cryogenic suction in freezing soil to matric suction in unsaturated soils and developed a thermohydromechanical coupled formulation, and Zhang and Michalowski [17] presented an elastic-plastic constitutive model to study the water and heat transfer of soil in freezing and thawing cycle. However, all of these typical models mentioned above did not address the salt transport, not to mention the precipitation.

To investigate the characteristics of water migration and salt transport of soil, a number of works have been carried out in lab experiment and modeling analysis. De Josselin De Jong [18] firstly studied the characteristics of soluble transport by analyzing the soil diffusion. Pariente [19] considered the environmental effect on soluble transport and studied dynamics of soluble salts concentration under different climatic conditions. Even though some scholars focused on the model coupled water heat and salt [20,21], little effort has been devoted to describe the phenomenon of precipitation in salt transport. Recently, some efforts are carried out for studying the characteristics of moisture and salt transfer [22, 23] and considering the precipitation [24]. However, all of these models were merely developed under the evaporation condition. From all the above, less effort has been made to investigate the phase transformation relationship between ice and water, the salt transport, and the precipitation under the freezing condition.

By analyzing the relationships among the different fields, this paper established coupled model of hydrothermal-salt for saturated salinized soil under the freezing condition and calculated by numerical simulation. The description of the coupled model is based on the relative volume of the soil elements. In the freezing process, soil-water potential is the driving force of water migration, which can be derived by Dancy's law and Clapyron equation. Besides, the precipitation can always be seen in the process of salt transport; the distribution of precipitation at different times has a certain characteristic; thus precipitation is considered in this study. By using the one-dimension experiment of moisture and salt transfer, the reliability of the mathematical model is demonstrated. And this study is to present an effective model to evaluate the water and salt transfer in the saturated soil under the condition of freezing for engineering purposes.

\section{Experiment to Typical Conditions}

As we know, western Jilin is one of typical seasonal frozen soil distribution areas of northeast China, which has a large amount of salinity. The climate is monsoon climate of medium latitudes. It is dry and windy in spring and autumn, and it has torrid summer and severe cold winter. The rainy season is June and August. For the strong evaporation in spring, salinity gathered and precipitated in the surface. And for the freezing effect in winter, the water migration brings the salinity to the freezing front. When spring comes, the salinity gathered once more in the surface [3]. The soil in western Jilin has massive amount of sodium and has the property of dispersity [25]. Thus soil in western Jilin has the properties of seasonally frozen soil, salinized soil, and dispersive soil. Evaporation and freezing are important reasons of soil salinization in this area. Thus to study forming mechanism of the salinized soil, water migration and salt transport in the process of freezing and evaporation need to be studied. And this paper presented an experiment and a mathematical coupled model to model the process of freezing in winter.

2.1. Experimental Material. The soil studied in this paper is collected from the Nong'an County, western Jilin, which is showed in Figure 1. For this area, freezing has a great influence on the soil properties. Freezing soil consists of mineral, organic matter, unfrozen water, ice, air, and microorganism. In this study, action of microorganism is ignored. The mineral and organic matter constitute soil particles. In the soil, soil skeleton is established by the soil particles. The liquid and gas are filled with the pores of the soil skeleton. For the frozen or freezing soil, ice phase needs to be taken into consideration. In this paper, a theoretical coupled model of hydrothermal-salt for saturated soil is presented; thus air is ignored. And a saturated salinized soil subjected to freezing is simulated and verified by experimental data in order to study the phase change characteristics between liquid water and ice. Figure 2 is the composition diagrammatic sketch of the saturated freezing soil and the right part of Figure 2 gives the relative volume.

In the saturated soil mass, the relationship of volume and quality between each component, including liquid water, ice, and soil particles, can be given as the following equations:

$$
\begin{aligned}
\rho & =\frac{M}{V} ; \\
\rho_{d} & =\frac{M_{s}}{V} ; \\
\rho_{s} & =\frac{M_{s}}{V_{s}} ; \\
e & =\frac{V_{p}}{V_{s}} ; \\
n & =\frac{V_{p}}{V} ; \\
W_{u} & =\frac{M_{\mathrm{uw}}}{M_{s}},
\end{aligned}
$$




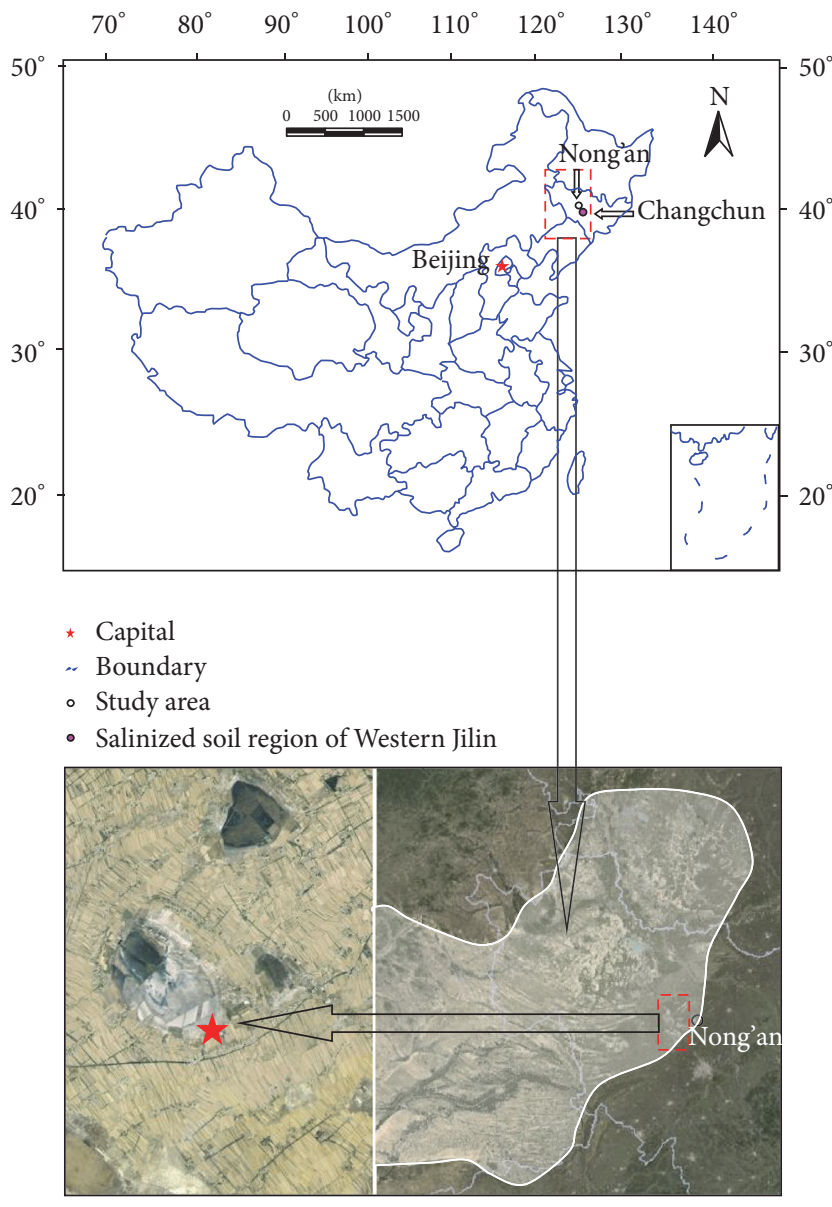

FIGURE 1: Location map of soil sampling point.

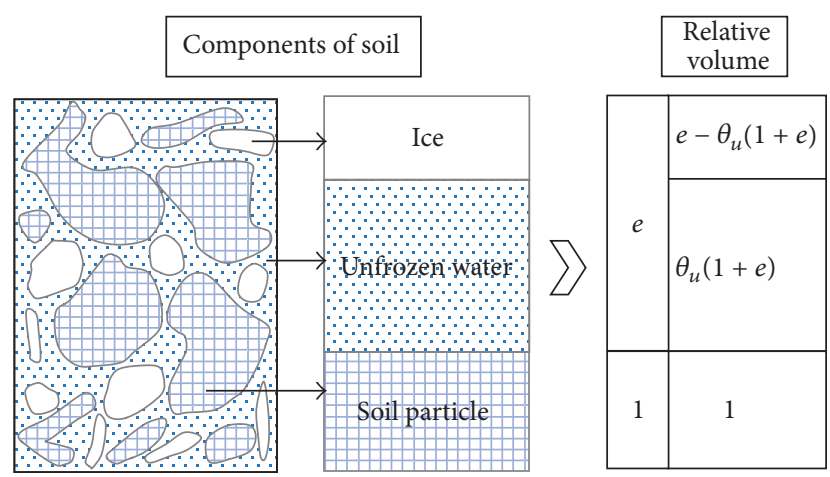

FIGURE 2: Component diagram of saturated freezing soil.

in which $M$ is total mass of the soil, $M_{s}$ is the mass of soil particles, $M_{\mathrm{uw}}$ is the mass of unfrozen water, $V$ is the total volume of the soil mass, $V_{p}$ is the volume of the pore, $\rho, \rho_{d}$, and $\rho_{s}$ are soil density, dry density, and soil particle density, $n$ is porosity, $e$ is the void ratio, and $W_{u}$ is the unfrozen water content.

In the process of freezing, not all the liquid water turns into ice. And some water remains unfrozen in this process. Since the content of unfrozen water depends on the soil

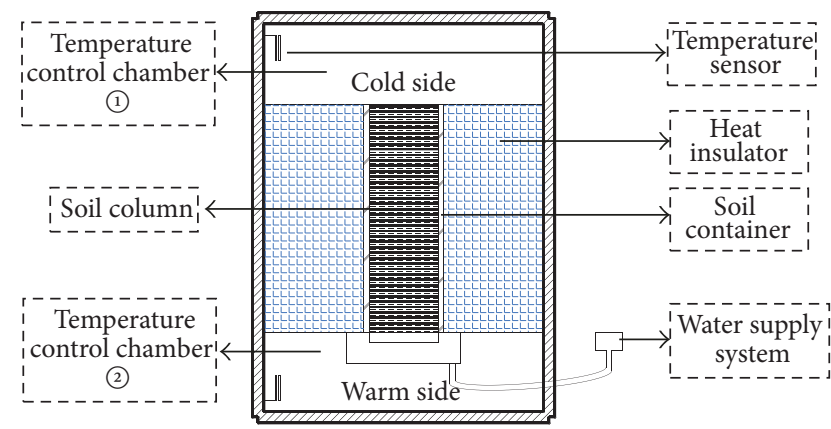

Figure 3: A schematic illustration of the experimental apparatus.

texture (including mineral, chemical component, density, and salinity), environmental condition, history of freezing and thawing, and so forth [26], thus unfrozen water content can be expressed using the following equation $[27,28]$ :

$$
W_{u}=A|T|^{-B}
$$

in which $W_{u}$ is the unfrozen water content; $T$ is the temperature, which is negative; $A$ and $B$ are the empirical coefficients related to the soil properties and content of salt. In this paper, $A=30.29$ and $B=-0.3569$, which are tested in the previous research [29]. By converting the relative volumes of the three phases of materials the unfrozen water volume content of soil $\theta_{u}$ can be expressed by the following equation according to Figure 1:

$$
\theta_{u}=\frac{\rho_{s}}{\rho_{w}(1+e)} W_{u}=\frac{\rho_{d}}{\rho_{w}} W_{u}
$$

When the temperature is lower or equal to the freezing temperature $T_{f}$, the unfrozen water volume content of the soil can be expressed by substituting (2) into (3):

$$
\theta_{u}=\frac{\rho_{d}}{\rho_{w}} A|T|^{-B}
$$

2.2. Experimental Apparatus. The experimental system consisted of temperature control chamber, refrigerating system, and water supply system. A schematic illustration of the experimental apparatus is shown in Figure 3. And the oneside freezing experiment was carried out in the open system. The soil used in this experiment is salinized soil collected from western Jilin and the particle size distribution is given in Figure 4. The maximum dry density of the soil is $1.68 \mathrm{~g} / \mathrm{cm}^{3}$. Considering that the optimum water content of the soil is $22 \%$, the soil sample is mixed with the water content of $22 \%$. And the soil sample is compacted as a column, $20 \mathrm{~cm}$ in height and $5 \mathrm{~cm}$ in diameter. The initial concentration of the salt in the water is equal to $2.73 \%$ and the solubility of the salt is $3.9 \%$. Before the experiment, the sample was put into a temperature control chamber for $24 \mathrm{~h}$, of which the temperature was set as $+2^{\circ} \mathrm{C}$. Then the soil sample was conducted to the one-side freezing experiment. The top temperature of the soil column is adjusted as $-5^{\circ} \mathrm{C}$ by the temperature control chamber (1), while the temperature of 


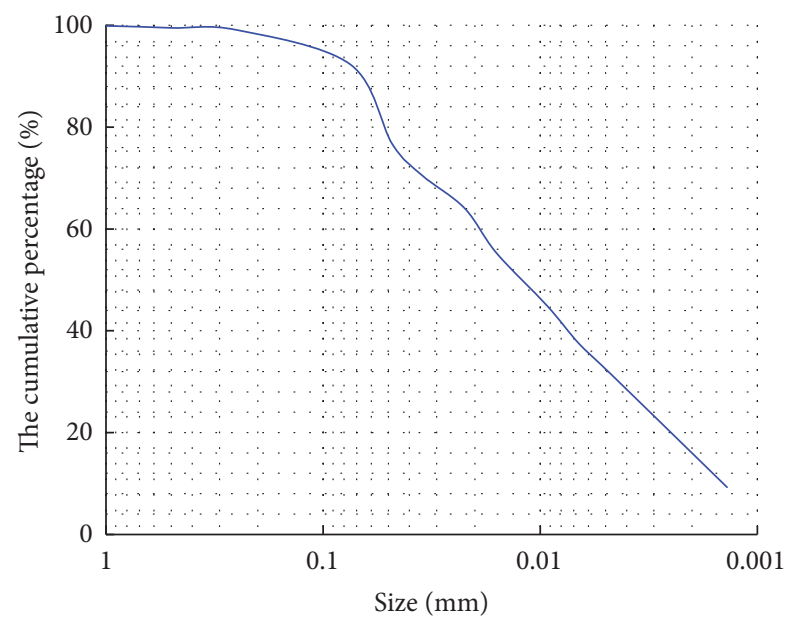

FIGURE 4: Particle size distribution of the studied soil.

the bottom is kept as $+2^{\circ} \mathrm{C}$. The side wall of the soil column is adiabatic. Also, solution of same concentration is applied freely at the bottom of soil column for the water supply and salt supply; namely, the water content and concentration at the bottom are invariant. The experiment last for $96 \mathrm{~h}$ in total. After the experiment, the sample was cut into pieces of $2 \mathrm{~cm}$ thickness and for the test of water content and content of salt.

According to the experiment, the dry density is $1.68 \mathrm{~g} / \mathrm{cm}^{3}$ and the initial water content is $22 \%$, and the water content can be expressed as the void ratio. The initial void ratio of the soil is calculated as 0.6 . In the process of the experiment, the boundary condition of bottom void ratio is set as 0.6 because it is supplied with the water. The boundary of top void ratio is set as 0.654 , because the top side is frozen instantly and the water volume is considered increasing by $9 \%$. The initial temperature of the soil is $+2^{\circ} \mathrm{C}$, the boundary of top temperature is $-5^{\circ} \mathrm{C}$, and the boundary of bottom temperature is $+2^{\circ} \mathrm{C}$. The initial concentration is $2.73 \%$, and bottom concentration boundary is set as $2.73 \%$ because of the salt supply.

\section{Theoretical Model}

In order to study the coupled model, the mathematical description of water migration, heat transfer, and salt transport are presented in this section. Heat transfer obeys energy conservation, and water and salt migration obeys the law of mass conservation. A typical representative volume element (RVE) is selected in this paper to analyze, as showed in Figure 5. Several pieces of assumption need to be developed in the process of mathematical modeling as follows:

(1) The soil studied is homogeneous and isotropic.

(2) Heat transfers in the forms of conduction and convection, irrespective of radiation.

(3) Water migration follows Darcy's law $[6,30]$.

(4) The soil particle is rigid body, and its volume is constant.

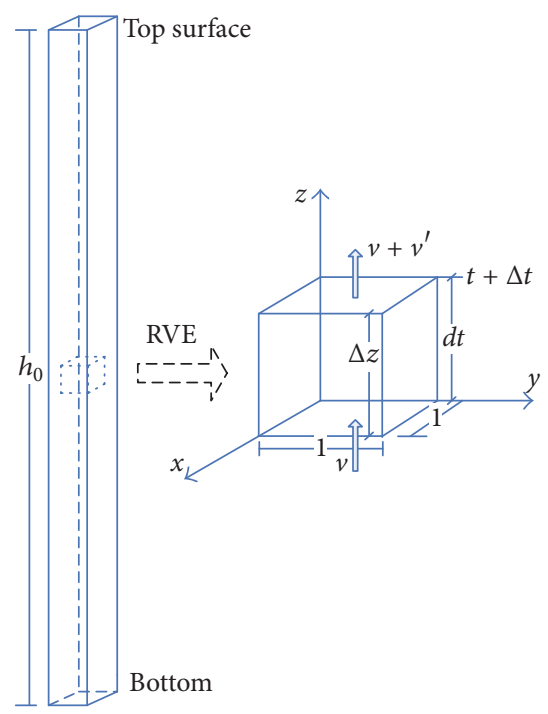

FIGURE 5: Representative volume element (RVE) schematic of onedimensional migration.

(5) In this coupling process, the volume change caused by frost heave and salt expansion is ignored.

3.1. Water Migration Equation. Based on the mass conservation equation, the water migration equation in vertical direction can be expressed as

$$
\frac{\partial m}{\partial t}=\frac{\partial\left(m_{w}+m_{i}\right)}{\partial t}=-\rho_{w} \frac{\partial v}{\partial z} d z d A
$$

in which $m_{w}$ is the mass of the liquid water and $m_{i}$ is the mass of ice and $v$ is the moisture migration flux.

It can also be obtained according to Figure 1.

$$
\begin{aligned}
& m_{w}=\rho_{w} \theta_{u} d V=\rho_{w} \frac{\theta_{u}(1+e)}{1+e} d V, \\
& m_{i}=\rho_{i} \frac{e-\theta_{u}(1+e)}{1+e} d V \\
& d V=(1+e) d V_{s} .
\end{aligned}
$$

And based on Darcy's law, the moisture migration flux is given as

$$
v=-k \frac{\partial \psi}{\partial z} .
$$

Substituting the equations of (2), (3), (4), and (5) into (1) gives

$$
\begin{gathered}
\frac{\partial\left[\rho_{w} \theta_{u}(1+e) d V_{s}+\rho_{i}\left(e-\theta_{u}(1+e)\right) d V_{s}\right]}{\partial t} \\
=\rho_{w} \frac{\partial}{\partial z}\left(k \frac{\partial \psi}{\partial z}\right)(1+e) d V_{s} .
\end{gathered}
$$

Derived from assumption (4) that the soil particles volume is constant, (8) is rearranged and showed as follows:

$$
\frac{\rho_{w}-\rho_{i}}{\rho_{w}} \frac{\partial \theta_{u}}{\partial t}+\frac{\rho_{i}+\left(\rho_{w}-\rho_{i}\right) \theta_{u}}{\rho_{w}(1+e)} \frac{\partial e}{\partial t}=\frac{\partial}{\partial z}\left(k \frac{\partial \psi}{\partial z}\right)
$$


in which $\psi$ is the soil-water potential, which is the sum of gravitational potential, temperature potential, pressure potential, and solute potential; and it can be expressed as [29]

$$
\psi=\psi_{g}+\psi_{T}+\psi_{p}
$$

In the formula, $\psi_{g}$ is gravitational potential, which is linear function of the position; $\psi_{T}$ is the temperature potential; and $\psi_{p}$ represents pressure potential.

The relationship between the press and temperature under the condition of phase equilibrium can be expressed by Clapeyron equation [6]. In previous research, the mathematical relationship between the temperature and pore water pressure has been derived based on Clapeyron equation, which is listed as follows [13]:

$$
\begin{aligned}
& u_{w} \\
& =\frac{\left(\rho_{w}-\rho_{i}\right)(1-\chi) p_{0}+\rho_{w} \rho_{i}(1-\chi) L \ln \left(T / T_{0}\right)+\rho_{w} u}{\left(\rho_{w}-\rho_{i}\right) \chi+\rho_{i}} \\
& u=\chi u_{w}+(1-\chi) u_{i}
\end{aligned}
$$

in which $u$ is the total pore pressure; it can be expressed by pore water pressure $u_{w}$ and pore ice pressure $u_{i}$. And $\chi$ is the proportion coefficient, which can be expressed using void ratio as $\chi=\left(\theta_{u}(1+e) / e\right)^{1.5}$.

In this paper, soil is supposed as homogeneous, and the effect of the solute potential is ignored so that the model can be simplified, solved, and modeled. The soil-water potential can be expressed as the form of water head by dimensional transformation. In the soil, gravitational potential is the function of position; thus it can be easily treated as the water head $z$; according to (11), the temperature potential $\psi_{T}$ and press potential $\psi_{p}$ can be comprehensively expressed as form of pore water pressure. The pore water pressure can be expressed as the form of water head $u_{w} / \rho_{w} g$. Thus the soilwater potential can be given as

$$
\psi=z+\frac{u_{w}}{\rho_{w} g} .
$$

3.2. Heat Transfer Equation. Normally, heat transfers in three modes, which are conduction, convection, and radiation. In this study, both heat conduction at different position under the temperature gradient and heat loss caused by convection during the process of water migration are taken into consideration.

It can be obtained that the relationship between the heat flux and temperature according to Fourier Law, is as follows:

$$
q_{c 1}=-\lambda \frac{\partial T}{\partial z}
$$

Heat Conduction

$$
\Delta Q_{1}=-\frac{\partial q_{c 1}}{\partial z} d V=\frac{\partial}{\partial z}\left(\lambda \frac{\partial T}{\partial z}\right) d V
$$

Heat Convection

$$
\Delta Q_{2}=-C_{w} v \frac{\partial T}{\partial z} d V
$$

By using the principle of conservation of energy, onedimensional heat transfer differential equation is established:

$$
C \frac{\partial T}{\partial t} d V-L \frac{\partial m_{i}}{\partial t}=\frac{\partial}{\partial z}\left(\lambda \frac{\partial T}{\partial z}\right) d V-C_{w} v \frac{\partial T}{\partial z} d V
$$

In this equation, the first item in the left side is the total heat change in the representative volume element; and the second item is heat loss caused by phase change. $L$ is phase change latent heat $L=334.56 \mathrm{~J} / \mathrm{g} ; \lambda$ is thermal conductivity coefficient and is expressed as $\lambda=$ $\lambda_{s}{ }^{1 /(1+e)} \lambda_{w}{ }^{\theta_{u}(1+e) /(1+e)} \lambda_{i}{ }^{\left(e-\theta_{u}(1+e)\right) /(1+e)}$, in which $\lambda_{s}$ is the soil particles thermal conductivity, $\lambda_{w}$ is thermal conductivity of water, and $\lambda_{i}$ is thermal conductivity of ice; $C$ is the specific heat and can be calculated as $C=(1 /(1+e))\left[C_{s}+\theta_{u}(1+\right.$ $\left.e) C_{w}+\left[e-\theta_{u}(1+e)\right] C_{i}\right]$, in which $C_{s}$ is the soil particles specific heat, $C_{w}$ is water specific heat, and $C_{i}$ is ice specific heat, respectively.

Substituting (6) and $\lambda, C$ into (17) gives

$$
\begin{gathered}
\left(C+L \rho_{i} \frac{\partial \theta_{u}}{\partial T}\right) \frac{\partial T}{\partial t}-\frac{L \rho_{i}\left(1-\theta_{u}\right)}{1+e} \frac{\partial e}{\partial t} \\
=\frac{\partial}{\partial z}\left(\lambda \frac{\partial T}{\partial z}\right)+C_{w} k \frac{\partial \psi}{\partial z} \frac{\partial T}{\partial z} .
\end{gathered}
$$

3.3. Solute Transport Equation. Solute transport process is supposed to be dissolved into water. In the process of solute transport, if the solute concentration is over its solubility, the excess salt cannot dissolve into water; and a small part of the excess salt is free in the solvent, while most of the excess salt will be precipitated. Considering the phenomenon of precipitation in solute transport, the solute transport equation is described as follows:

$$
\begin{aligned}
\frac{\partial\left(\rho_{w} \theta_{u} c\right)}{\partial t} & =-\frac{\partial \rho_{w} v c}{\partial z}+\nabla\left[\rho_{w} \theta_{u}\left(D_{i}+D_{m}\right) \frac{\partial c}{\partial z}\right]-\kappa \\
\frac{\partial K}{\partial t} & =\kappa \\
\nabla & =\frac{\partial}{\partial z}
\end{aligned}
$$

in which the item of the left side is solute transport rate; and the first item in the right side is advection, the second item is hydrodynamic dispersion, the third item is precipitation, respectively, and $D_{i}$ is the diffusive coefficient $D_{i}=5 \times 10^{-11}$. $w_{u}$, where $w_{u}$ is the unfrozen water content and $D_{m}$ is the coefficient of mechanical dispersion, which can be calculated by $D_{m}=0.35 v[4]$

On the basis of Figure 6 and allowing solute concentration to exceed the solubility, the total salt mass per unit volume of soil can be expressed as

$$
M= \begin{cases}\theta_{u} \cdot \rho_{w} \cdot c & 0 \leq c \leq c_{s} \\ \theta_{u} \rho_{w} c_{s}+k\left(c-c_{s}\right) & c \geq c_{s} .\end{cases}
$$

In this equation, $k$ is the slope of the precipitation part, and this part can be considered as a virtual medium. In this 


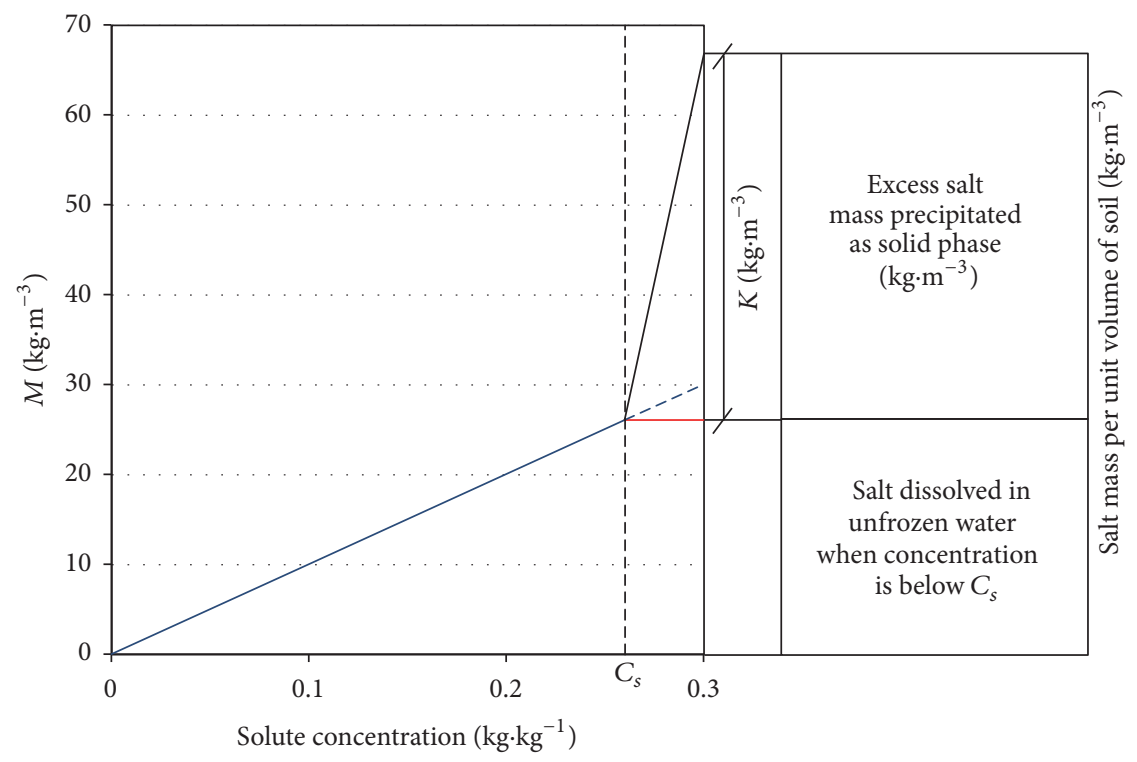

FIGURE 6: Salt mass (solid and solute) per unit volume of soil versus solute concentration $c$.

paper, the slope of this virtual medium $k$ can be set as a large value; and in modeling, value of the slope is suggested as $1000 \mathrm{~kg} \cdot \mathrm{m}^{-3}$.

Besides, the excess salt mass that precipitates per unit volume of soil gives

$$
K= \begin{cases}0 & c \leq c_{s} \\ k\left(c-c_{s}\right) & c>c_{s} .\end{cases}
$$

3.4. Relationship of Water, Heat, and Salt. In freezing process, water, heat, and salt interact. With the temperature gradient, heat transfers from the high temperature to the low temperature. And the unfrozen water migrates from the high temperature to the low temperature and gathers around the freezing front under the temperature gradient. In the water migration, the salt is dissolved in the water and transported. In addition, water migration can affect heat transfer because of the heat convection and phases change in the process of freezing. To illustrate the interactive mechanism, the coupled model of hydrothermal-salt for saturated freezing salinized soil is presented in mathematics as the following governing equations.

Hydraulic

$$
\frac{\rho_{w}-\rho_{i}}{\rho_{w}} \frac{\partial \theta_{u}}{\partial t}+\frac{\rho_{i}+\left(\rho_{w}-\rho_{i}\right) \theta_{u}}{\rho_{w}(1+e)} \frac{\partial e}{\partial t}=\frac{\partial}{\partial z}\left(k \frac{\partial \psi}{\partial z}\right)
$$

Thermal

$$
\begin{gathered}
\left(C+L \rho_{i} \frac{\partial \theta_{u}}{\partial T}\right) \frac{\partial T}{\partial t}-\frac{L \rho_{i}\left(1-\theta_{u}\right)}{1+e} \frac{\partial e}{\partial t} \\
=\frac{\partial}{\partial z}\left(\lambda \frac{\partial T}{\partial z}\right)+C_{w} k \frac{\partial \psi}{\partial z} \frac{\partial T}{\partial z} .
\end{gathered}
$$

Salt

$$
\frac{\partial\left(\rho_{w} \theta_{u} c+k c\right)}{\partial t}=\nabla\left[-\rho_{w} v c+\rho_{w} \theta_{u}\left(D_{i}+D_{m}\right) \frac{\partial c}{\partial z}\right] .
$$

\section{Simulation to the Typical Conditions}

4.1. Numerical Simulation. Based on the coupled model on water heat and salt of salinized soil, this paper analyzed the process by applying finite element software COMSOL Multiphysics. The initial conditions and boundary conditions of simulation were the same as those of the experiment, which are as follows: $\left.e\right|_{t=0}=0.6,\left.T\right|_{t=0}=+2^{\circ} \mathrm{C},\left.c\right|_{t=0}=2.73 \%,\left.e\right|_{z=0}=$ $0.6,\left.e\right|_{z=0.2}=0.654,\left.T\right|_{t=0}=+2^{\circ} \mathrm{C},\left.T\right|_{z=0}=+2^{\circ} \mathrm{C},\left.T\right|_{z=0.2}=$ $-5^{\circ} \mathrm{C}$, and $\left.c\right|_{z=0}=2.73 \%$, where $t$ is the freezing time and $z$ is the position. According to the first assumption, material and heat migration in horizontal direction are ignored, and this can be treated as one-dimensional material and heat migration problem. In this numerical simulation, 200 elements are generated along with the soil column direction, calculating step length is $1 \mathrm{~h}$, and freezing time is $96 \mathrm{~h}$. By transient analysis, the simulation results of water distribution, temperature distribution, and salt distribution are obtained. The initial permeability value is measured in the laboratory. The soil particles thermal conductivity $\lambda_{s}$ is obtained in the laboratory, and the water thermal conductivity $\lambda_{w}$ and ice thermal conductivity $\lambda_{i}$ are constant. The soil particles specific heat $C_{s}$ is obtained in the laboratory, and water specific heat $C_{w}$ and ice specific heat $C_{i}$ are constant. $L$ is the phase change latent heat and it is constant. All the values of parameters in numerical simulation are showed in Table 1. Besides, permeability is a function of temperature in freezing soil $[6,12]$, which can be expressed as

$$
k= \begin{cases}k_{0}\left[1-\left(T-T_{f}\right)\right]^{\beta} & T \leq T_{f} \\ k_{0} & T>T_{f},\end{cases}
$$


TABLE 1: Parameters and the value.

\begin{tabular}{lcc}
\hline Parameters & Value & Unit \\
\hline$L$ & $3.3456 \times 10^{5}$ & $\mathrm{~J} \cdot \mathrm{kg}^{-1}$ \\
$P_{0}$ & $1.01 \times 10^{5}$ & $\mathrm{~Pa}$ \\
$\lambda_{s}$ & 4320 & $\mathrm{~J} \cdot \mathrm{h}^{-1} \cdot \mathrm{m}^{-1} \cdot \mathrm{K}^{-1}$ \\
$\lambda_{w}$ & 2088 & $\mathrm{~J} \cdot \mathrm{h}^{-1} \cdot \mathrm{m}^{-1} \cdot \mathrm{K}^{-1}$ \\
$\lambda_{i}$ & 7992 & $\mathrm{~J} \cdot \mathrm{h}^{-1} \cdot \mathrm{m}^{-1} \cdot \mathrm{K}^{-1}$ \\
$A$ & 30.29 & \\
$B$ & -0.3569 & \\
$e_{z=0}$ & 0.6 & \\
$W_{u}$ & $22 \%$ & $\mathrm{~J} \cdot \mathrm{m}^{-3} \cdot \mathrm{K}^{-1}$ \\
$C_{s}$ & $2217 \times 10^{3}$ & $\mathrm{~J} \cdot \mathrm{m}^{-3} \cdot \mathrm{K}^{-1}$ \\
$C_{w}$ & $4180 \times 10^{3}$ & $\mathrm{~J} \cdot \mathrm{m}^{-3} \cdot \mathrm{K}^{-1}$ \\
$C_{i}$ & $1874 \times 10^{3}$ & $\mathrm{~m} \cdot \mathrm{s}^{-1}$ \\
$k_{0}$ & $0.9 \times 10^{-6}$ & $\mathrm{~kg} \cdot \mathrm{kg}^{-1}$ \\
$c_{0}$ & 2.73 & \\
$e_{z=0.2}$ & 0.654 & \\
$e_{0}$ & 0.6 & \\
\hline
\end{tabular}

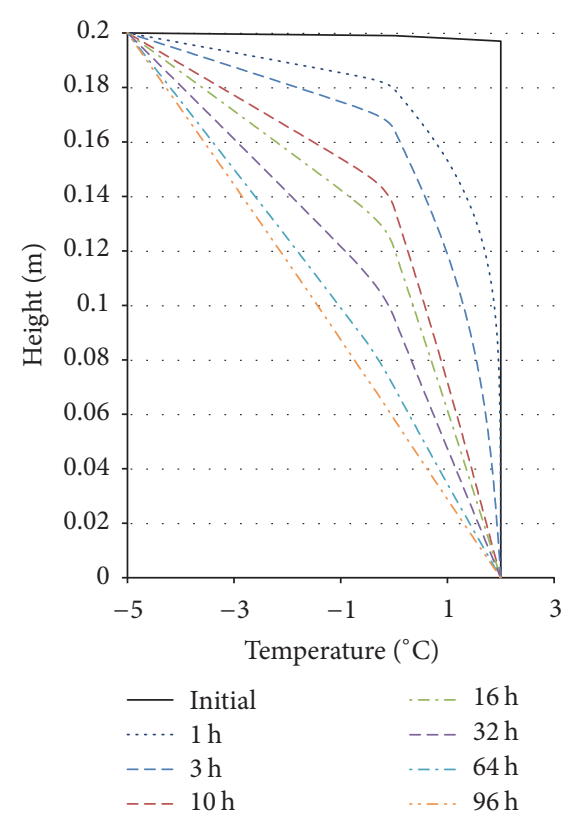

Figure 7: Distribution of the temperature at different times.

where $k_{0}$ is the initial permeability of unfrozen soil and $\beta$ is a coefficient which is suggested as -8 .

\section{Results and Discussion}

5.1. Temperature Field Analysis. Temperature distribution in the process of freezing is showed in Figure 7. According to Figure 7, it is obvious that the initial temperature of the top side is $-5^{\circ} \mathrm{C}$, and the freezing front is close to the top surface at beginning. With the freezing time increasing, the freezing front constantly moves down along with the soil column, leading to the increase of frozen area and decrease of unfrozen area. When the freezing time reaches $96 \mathrm{~h}$,

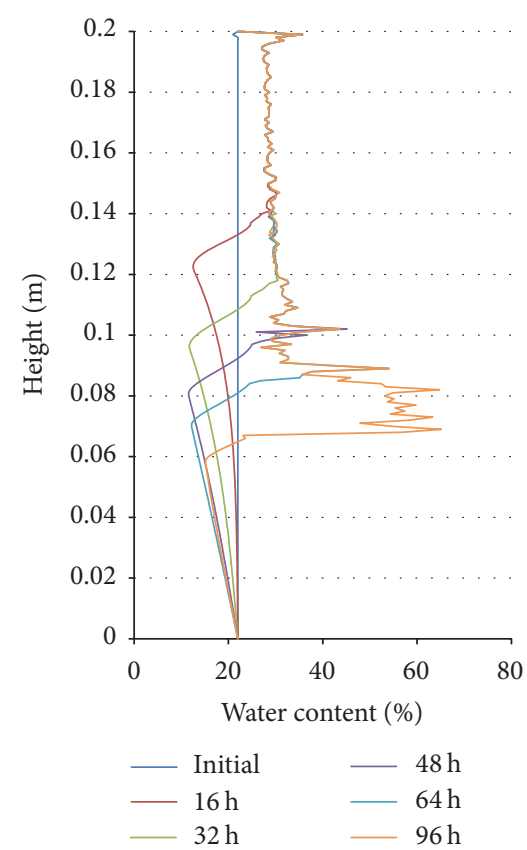

FIGURE 8: Water content distribution along soil column at different time.

distribution characteristics of temperature along the column tend to be stable. The dynamic changes of the temperature distribution at different time can also be observed. Within the first $16 \mathrm{~h}$, the distribution of temperature changes a lot, while after $16 \mathrm{~h}$, the distribution of temperature changes not that obvious. Also, it can be easily found that every curve has an inflexion, which reflects the freezing front and the boundary between frozen zone and unfrozen zone; it is frozen zone above this position and it is unfrozen zone below this position. As time increases, the inflexion point moves down along with the column, which indicates that the freezing front moves down with time going. Besides, the inflexion also reflects that the temperature gradient of the frozen zone is higher than that of unfrozen zone.

5.2. Moisture Field Analysis. With one-side freezing, moisture in the soil migrates continually under the driving force of soil-water potential. Figure 8 gives the simulated distribution of the water content, and it can be observed from Figure 8 that the water content of the upper part is increasing; meanwhile, the water content decreases in the lower part. As a result, the simulation result indicates that with freezing time increasing the frozen area increases and unfrozen area decreases. Water migrates from unfrozen zone to the freezing front, and the freezing front moves down continually; thus moisture content of the frozen zone increases. When freezing time reaches $64 \mathrm{~h}$, it can be found that a large amount of water migrates to the frozen zone. It is because the temperature gradient of frozen zone becomes smaller and smaller after $64 \mathrm{~h}$, distribution of temperature tends to be stable, and the freezing front moves slowly. Thus there is relative more time for unfrozen water to migrate. Similarly, it can also be observed that the freezing front continually moves 


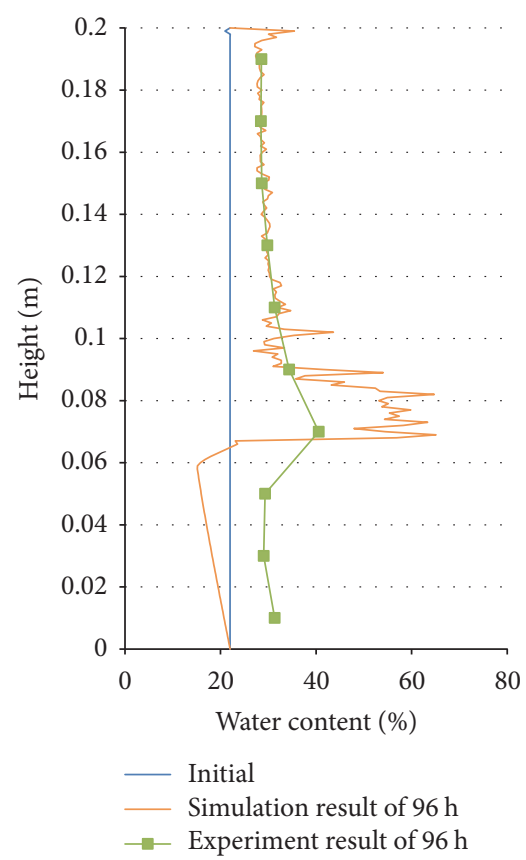

FIGURE 9: Water content distribution between simulation and experiment.

downwards. At all the time, the water under the freezing front migrates to the frozen zone. When the freezing time reaches $96 \mathrm{~h}$, moisture content at the position around $7 \mathrm{~cm}$ is the highest; the reason is that the distribution of the temperature approximates to being linear and tends to be stable after $96 \mathrm{~h}$. Besides, the temperature of $7 \mathrm{~cm}$ is close to the freezing front, and it also tends to be stable at this position. Thus lots of water has enough time to migrate to this freezing front. Figure 9 gives the compared result of moisture content after the experiment. After $96 \mathrm{~h}$, the distribution along the soil column is stable. It can be seen that moisture content of the soil column increases, and the moisture content at the height of $7 \mathrm{~cm}$ is the highest, which indicated that simulation results agree well with the experimental results.

In order to study the characteristics of water migration, the pore size distribution of the specimen before freezing is tested by using the AUTO-PORE 9500 Mercury injection apparatus. After the experiment, a typical soil specimen at $11 \mathrm{~cm}$ is also cut for testing the pore size distribution. Figure 10(a) gives the pore size distribution curves of specimens before and after the freezing experiment. It can be seen that the proportion of the pores at the size of $0.8 \sim 10 \mu \mathrm{m}$ decreases obviously, but the proportion of the pores at the size of $0.03 \sim 0.8 \mu \mathrm{m}$ increases after the freezing experiment. As we know, the capillary size is mainly at the range of $2 \sim 500 \mu \mathrm{m}$ [31]; thus the large amount of water migration is caused by bound water migration rather than capillary water rise, which is similar to results presented by Yu [4]. To get deepened understanding of the pore size change characteristics, different partition methods have been proposed based on the pore size [32]. According to the literature [33], the pore of the clay can be divided into micropore $(<0.04 \mu \mathrm{m})$, fine pore

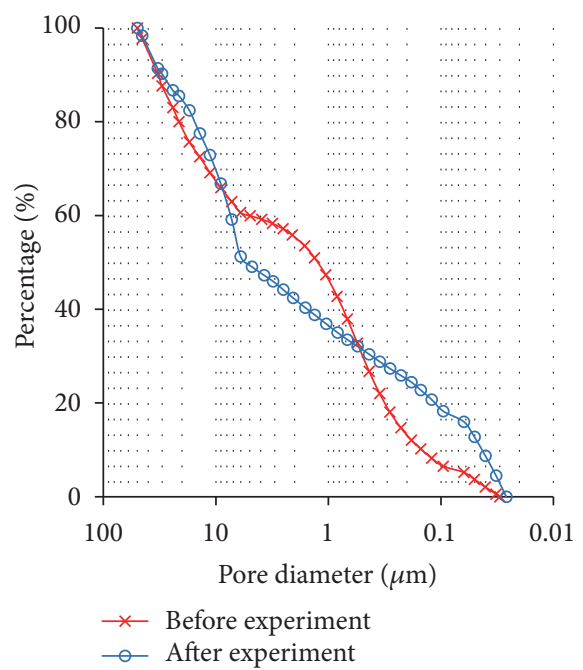

(a)

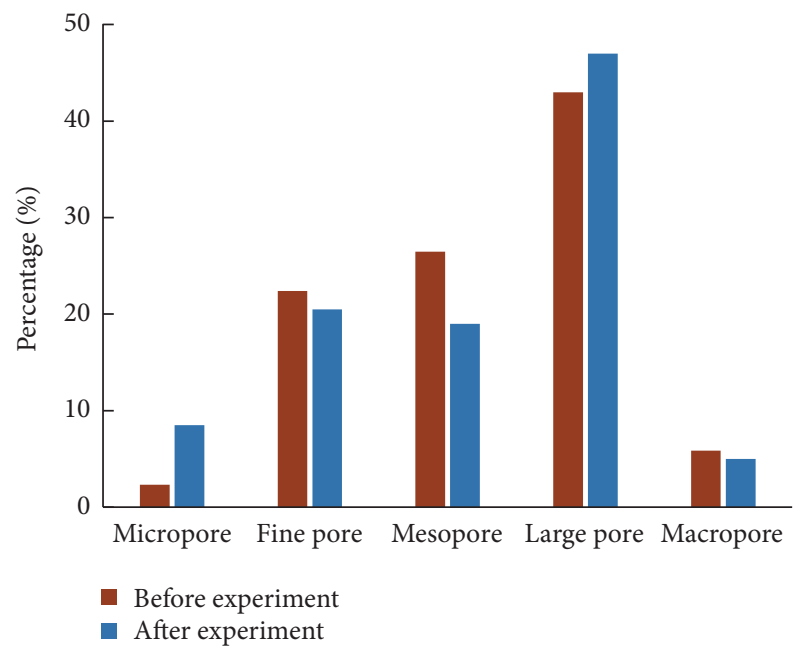

(b)

Figure 10: Pore size distribution before and after the freezing experiment.

(0.04 0.4 $\mu \mathrm{m})$, mesopore $(0.4 \mu \mathrm{m} \sim 4 \mu \mathrm{m})$, large pore $(4 \mu \mathrm{m} \sim$ $40 \mu \mathrm{m})$, and macropore ( $>40 \mu \mathrm{m})$. In the freezing process, water migrates through the soil and affects the soil structure by affecting the pore size. Instructed by this partition method, the pore distributions of different sections are also showed in Figure 10(b), indicating that the proportions of the fine pore and mesopore decrease, but the proportions of the micropore increase after freezing. Due to the increasing proportion of micropore, the bound water migrates massively through the micropore, leading to the increase of water content in the frozen zone.

5.3. Salt Field Analysis. Based on the research of salinized soil, salt field of the soil is simulated according to the coupled equation, and the transfer characteristic of salt in the process of freezing is obtained. Solute transports in two types of modes, which are advection and hydrodynamic dispersion. Figure 11 gives simulated content of the salt along with the 


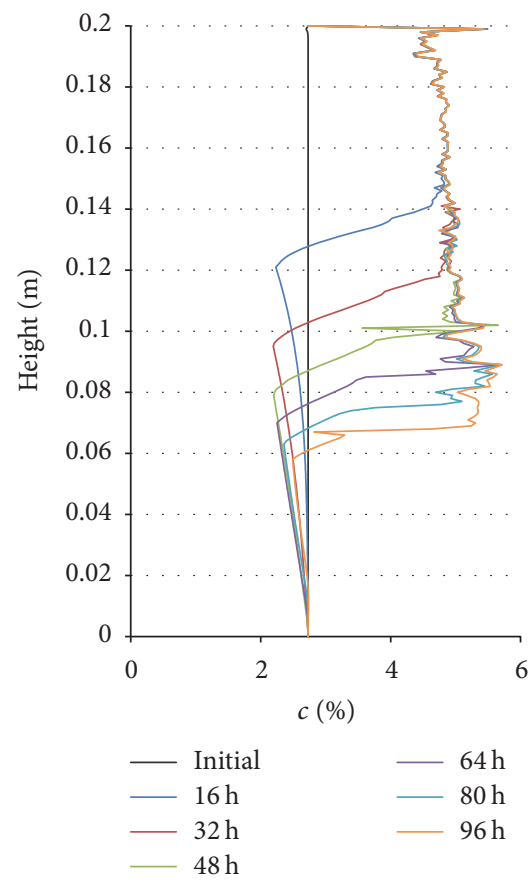

FIGURE 11: Salt concentration distribution along soil column at different time.

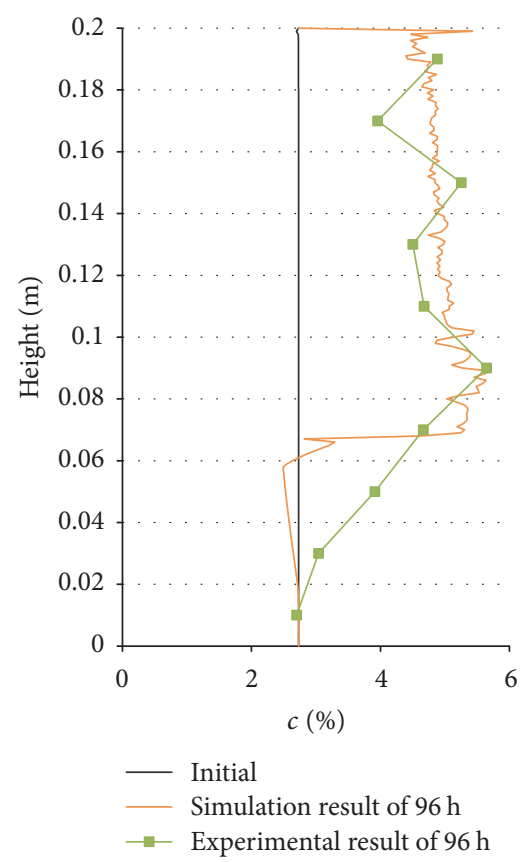

FIGURE 12: Salt concentration distribution between simulation and experiment.

soil column at different freezing times. The distribution characteristic of the salt is consistent with that of the water content. From Figure 12, it can be observed that salt content of the upper part increases; similarly, the content of salt in the unfrozen zone is decreasing. Therefore, simulation of salt transfer indicates that with the freezing time increasing

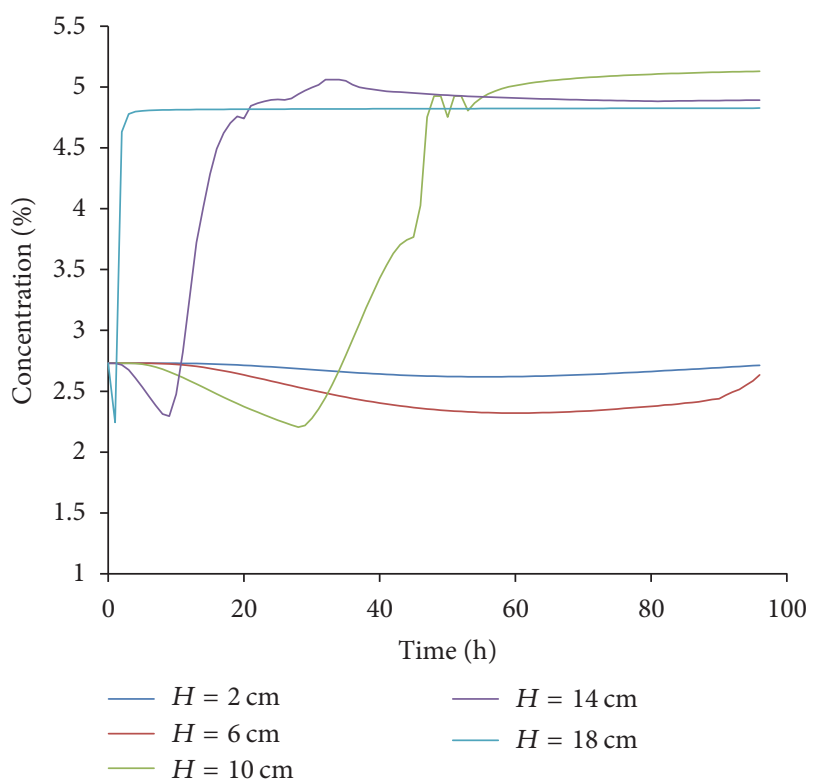

FIGURE 13: Salt concentration of the 5 typical positions.

salt of the unfrozen zone gradually transfers to the frozen zone, leading to the content of salt increases in frozen zone. Compare Figures 8 and 11; the migration characteristics of water and salt are similar. Thus the salt migrates mainly with water migration. However, at the beginning of freezing, salt migrates a lot but water migrates a little. It is because the salt migration includes not only advection but also hydrodynamic dispersion. Figure 12 shows the compared result of simulation and experiment after freezing $96 \mathrm{~h}$. It can be found that the simulation result tallies with the experiment data well. And in the unfrozen zone, the experimental result shows that salt concentration increases with the height increasing, which indicates salt still migrates upwards. In the soil column, 5 typical positions are selected to illustrate the dynamic changes of salt concentration. As showed in Figure 13, salt concentration in the position of $18 \mathrm{~cm}$ decreases at beginning and increases after $2 \mathrm{~h}$. This is because the freezing front moves downwards, and within $2 \mathrm{~h}$, it is above $18 \mathrm{~cm}$, which leads to salt concentration decrease at this position. After $2 \mathrm{~h}$, freezing front reaches $18 \mathrm{~cm}$; water and salt begin to migrate to the new freezing front, leading to salt concentration increase. In the process of freezing, freezing front keeps moving down and the salt concentration becomes stable when freezing front moved down to another position. Similarly, salt concentration in the positions of $14 \mathrm{~cm}$ and $10 \mathrm{~cm}$ decreases at first and then increases. It is obtained from Figure 6 that, after $96 \mathrm{~h}$, temperature distribution tends to be linear and freezing front is around the position of $7 \mathrm{~cm}$. The part below $7 \mathrm{~cm}$ in the soil column is unfrozen all the time; thus salt in this part migrates upwards all the time.

As we know, solute would precipitate when the concentration exceeds its solubility, and this paper takes the precipitation of the salt into consideration. In the process of salt transport, when the concentration of one position is over the solubility, it would be judged as precipitation. Figure 14 


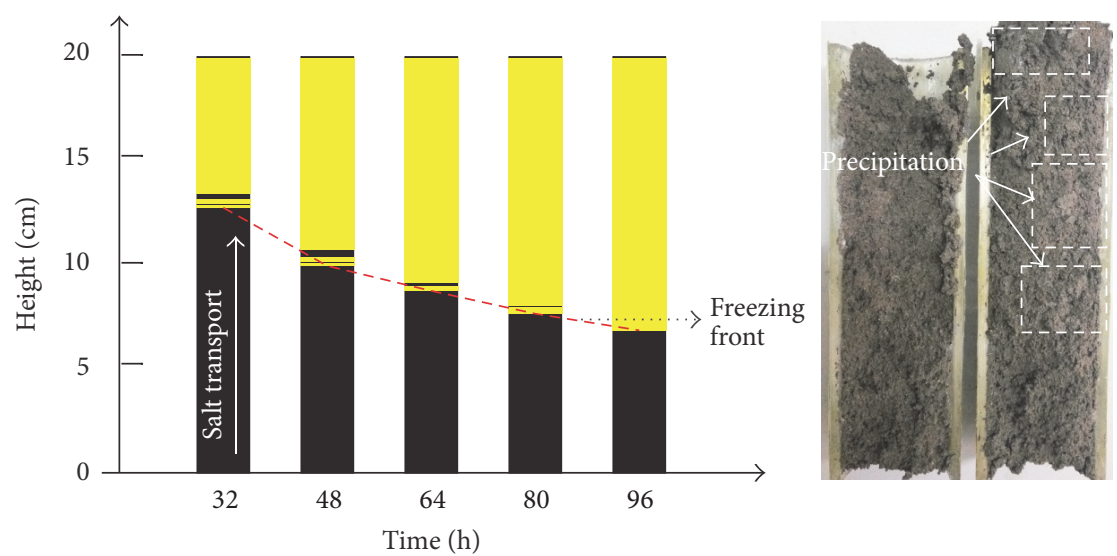

FIGURE 14: The distribution of precipitation between experiment and the simulation (the yellow parts are precipitations, and the right photo is the experimental result after $96 \mathrm{~h}$ ).

gives the simulated distribution of precipitation along with the soil column after $96 \mathrm{~h}$ between experiment and the simulation. With the freezing time increasing, the position of precipitation is distributed in the frozen zone. Similar to water content distribution, a lot of salt precipitates after $96 \mathrm{~h}$, and most precipitations are above the height of $7 \mathrm{~cm}$. In the process of migration, the salt migrates as solute in the water. The freezing front moves slowly when freezing time is close to $96 \mathrm{~h}$; water and salt migrate continually to the height of $7 \mathrm{~cm}$. Most of the water in this position would become ice; thus a amount of salt would precipitate above this position. From the photo of experiment, precipitation can be seen obviously above the position of $7 \mathrm{~cm}$. Compared with the experiment result, the simulation agrees well.

In this study, a mathematical model of moisture migration and salt transport in freezing saturated soil was presented and verified by the experimental result. Therefore, this model can be applied for calculations with the relevant calculation parameters.

\section{Conclusions}

On the basis of conservation of energy, conservation of mass, Darcy's law, and Clapeyron equation, this paper derived water migration equation, heat transfer equation, and solute transport equation and established the coupled model of hydrothermal-salt for saturated salinized soil under the freezing condition. In this model, precipitation phenomenon during the coupling process is considered. And the model is verified by the numerical simulations and laboratory experiment. Based on the analysis above, some conclusions can be drawn as follows.

(1) In the process of freezing, the different temperature gradients reflect the boundary between frozen zone and unfrozen zone. Unfrozen water always migrates to freezing front and the freezing front moves downwards, which leads to increase of water content in frozen zone. In this paper, when the freezing time reaches a certain time, the distribution of temperature tends to be stable, the freezing front is around $7 \mathrm{~cm}$, and the unfrozen water migrates to the freezing front continually. The particle size distribution before and after the freezing experiment indicates that the proportion of the micropore increases and the water content increase is caused by bound water migration.

(2) In simulation, transport characteristic of salt is similar to the migration characteristic of water. Salt also transports upwards, leading to increase in the salt concentration of frozen zone. During freezing, excess salt will be precipitated if salt concentration is greater than solubility and the precipitation would be distributed discontinuously along with the salt in freezing.

(3) The mathematical model is verified by the experimental data. And the simulation results show that the moisture content, content of soluble salt, and the positions of precipitation are generally consistent with the experimental results and laid the foundation for calculation of coupled moisture and salt in the freezing soil.

(4) This paper proposed a coupled model of water, heat, and salt for the salinized soil, verified by the numerical simulations and laboratory experiment. The author will study the engineering effect and disastrous evolution mechanism by studying the process coupling water heat salt and stress in the further study. And the author will consider the pore size distribution change caused by frost heave and salt expansion during freezing and verify its validity through the experiment.

\section{Nomenclature}

$\Psi:$ Soil-water potential

$\Psi_{g}$ : Gravitational potential

$\Psi_{T}$ : Temperature potential

$\Psi_{P}$ : Pressure potential

$\kappa: \quad$ Precipitation rate of salt per unit volume

$\theta_{u}$ : Unfrozen water volume content of soil 
$\rho: \quad$ Soil density, $\mathrm{kg} \cdot \mathrm{m}^{-3}$

$\rho_{d}: \quad$ Soil dry density, $\mathrm{kg} \cdot \mathrm{m}^{-3}$

$\rho_{s}: \quad$ Soil particle density, $\mathrm{kg} \cdot \mathrm{m}^{-3}$

$\rho_{w}: \quad$ Density of water, $1000 \mathrm{~kg} \cdot \mathrm{m}^{-3}$

$\rho_{i}$ : Density of ice, $917 \mathrm{~kg} \cdot \mathrm{m}^{-3}$

$\lambda$ : Thermal conductivity coefficient of soil

$\lambda_{s}: \quad$ Thermal conductivity of soil grains

$\lambda_{w}$ : Thermal conductivity of water

$\lambda_{i}$ : Thermal conductivity of ice

$\chi$ : $\quad$ Proportion coefficient

A: Empirical coefficients related to the soil properties

B: Empirical coefficients related to the soil properties

$C: \quad$ Specific heat, $\mathrm{J} \cdot \mathrm{m}^{-3} \cdot \mathrm{K}^{-1}$

$C_{s}: \quad$ Soil particles specific heat, $\mathrm{J} \cdot \mathrm{m}^{-3} \cdot \mathrm{K}^{-1}$

$C_{w}$ : Water specific heat, $\mathrm{J} \cdot \mathrm{m}^{-3} \cdot \mathrm{K}^{-1}$

$C_{i}: \quad$ Ice specific heat, $\mathrm{J} \cdot \mathrm{m}^{-3} \cdot \mathrm{K}^{-1}$

$D_{i}$ : $\quad$ Diffusive coefficient

$D_{m}$ : Coefficient of mechanical dispersion

$K: \quad$ Mass of solid salt per unit volume, $\mathrm{kg} \cdot \mathrm{m}^{-3}$

L: $\quad$ Phase change latent heat, $\mathrm{J} \cdot \mathrm{kg}^{-1}$

$M$ : Total mass of the soil

$M_{s}$ : Mass of soil particles

$M_{\mathrm{uw}}$ : Mass of unfrozen water

$P_{0}$ : Atmospheric pressure, $1.01 \times 10^{5} \mathrm{~Pa}$

$T$ : Temperature

$T_{f}$ : Freezing temperature

$V: \quad$ Total volume of the soil mass

$V_{p}$ : Volume of the pore

$V_{s}$ : Volume of the soil particle

$W_{u}$ : Unfrozen water content

$c$ : Solute concentration, $\mathrm{kg} \cdot \mathrm{kg}^{-1}$

$c_{s}: \quad$ Solubility, $\mathrm{kg} \cdot \mathrm{kg}^{-1}$

e: $\quad$ Void ratio

$g: \quad$ Gravitational acceleration, $9.8 \mathrm{~m} \cdot \mathrm{s}^{-2}$

$k$ : $\quad$ Permeability coefficient

$k_{0}$ : Initial permeability of unfrozen soil

$m_{w}$ : Mass of the liquid water

$m_{i}$ : Mass of ice

n: $\quad$ Porosity

$u$ : Total pore pressure

$u_{i}$ : Pore ice pressure

$u_{w}$ : Pore water pressure

$v$ : Moisture migration flux.

\section{Conflicts of Interest}

The authors declare that they have no conflicts of interest.

\section{Acknowledgments}

The authors are grateful for the financial support for the study presented in this paper from the State Key Program of the National Natural Science Foundation of China (no. 41430642) and the National Natural Science Foundation of China (Grant no. 41372267 and no. 41302247).

\section{References}

[1] A. Sarsembayeva and P. E. Collins, "Evaluation of frost heave and moisture/chemical migration mechanisms in highway subsoil using a laboratory simulation method," Cold Regions Science and Technology, vol. 133, pp. 26-35, 2017.

[2] J. Liu and Y. Tian, "Numerical studies for the thermal regime of a roadbed with insulation on permafrost," Cold Regions Science and Technology, vol. 35, no. 1, pp. 1-13, 2002.

[3] S. C. Bao, Q. Wang, X. H. Bao, and Z. Wang, "Characters of saline-alkali soil in western Jilin and biological treatment," Journal of Pure and Applied Microbiology, vol. 7, pp. 809-812, 2013.

[4] T. W. Yu, Numerical Analysis of Coupled Water Heat Salt and Stress of Saline Soil in Western Jilin Province, Jilin University, Changchun, China, 2016.

[5] J. S. Yang, "Development and prosect of the research on saltaffected soils in China," Acta Pedologica Sinica, vol. 45, no. 5, pp. 837-845, 2008.

[6] H. R. Thomas, P. Cleall, Y.-C. Li, C. Harris, and M. KernLuetschg, "Modelling of cryogenic processes in permafrost and seasonally frozen soils," Geotechnique, vol. 59, no. 3, pp. 173-184, 2009.

[7] R. L. Harlan, "Analysis of coupled heat-fluid transport in partially frozen soil," Water Resources Research, vol. 9, no. 5, pp. 1314-1323, 1973.

[8] S. Taber, "The mechanics of frost heaving," The Journal of Geology, vol. 38, no. 4, pp. 303-317, 1930.

[9] E. Penner, "The mechanism of frost heaving in soils," Highway Research Board Bulletin, vol. 22, pp. 1-22, 1959.

[10] S. J. Han and D. J. Goodings, "Practical model of frost heave in clay," Journal of Geotechnical and Geoenvironmental Engineering, vol. 132, no. 1, pp. 92-101, 2006.

[11] J. M. Konrad and N. R. Morgenstern, "The segregation potential of a freezing soil," Canadian Geotechnical Journal, vol. 18, no. 4, pp. 482-491, 2006.

[12] K. O’Neill and R. D. Miller, "Exploration of a rigid ice model of frost heave," Water Resources Research, vol. 21, no. 3, pp. 281-296, 1985.

[13] F. Ming and D.-Q. Li, "Experimental and theoretical investigations on frost heave in porous media," Mathematical Problems in Engineering, vol. 2015, Article ID 198986, 9 pages, 2015.

[14] C. Duquennoi, M. Fremond, and M. Levy, "Modeling of thermal soil behavior," VTT Symposium, vol. 95, pp. 895-915, 1989.

[15] M. Fremond and M. Mikkola, "Thermomechanical modelling of freezing soil," in Proceedings of the 6th International Symposium on Ground Freezing, pp. 17-24, Rotterdam, The Netherlands, 1991.

[16] S. Nishimura, A. Gens, S. Olivella, and R. J. Jardine, “THMcoupled finite element analysis of frozen soil: formulation and application," Géotechnique, vol. 59, no. 3, pp. 159-171, 2009.

[17] Y. Zhang and R. L. Michalowski, "Thermal-hydro-mechanical analysis of frost heave and thaw settlement," Journal of Geotechnical and Geoenvironmental Engineering, vol. 141, no. 7, 2015.

[18] G. De Josselin De Jong, "Longitudinal and transverse diffusion in granular deposits," Eos, Transactions American Geophysical Union, vol. 39, no. 1, pp. 67-74, 1958.

[19] S. Pariente, "Soluble salts dynamics in the soil under different climatic conditions," Catena, vol. 43, no. 4, pp. 307-321, 2001.

[20] J. Bear and A. H.-D. Cheng, Modeling Groundwater Flow and Contaminant Transport, Springer, Dordrecht, The Netherlands, 2010. 
[21] G. H. Yuan, The Mechanism and Numerical Simulation of Water Transfer in Seasonal Freezing Soil, Jilin University, Changchun, China, 2006.

[22] R. Li, H. Shi, G. N. Flerchinger, T. Akae, and C. Wang, "Simulation of freezing and thawing soils in Inner Mongolia Hetao Irrigation District, China," Geoderma, vol. 173-174, pp. 28-33, 2012.

[23] Q. Zhen, W. Ma, M. Li, H. He, X. Zhang, and Y. Wang, "Effects of vegetation and physicochemical properties on solute transport in reclaimed soil at an opencast coal mine site on the Loess Plateau, China," Catena, vol. 133, no. 3, pp. 403-411, 2015.

[24] C. Zhang, L. Li, and D. Lockington, "Numerical study of evaporation-induced salt accumulation and precipitation in bare saline soils: mechanism and feedback," Water Resources Research, vol. 50, no. 10, pp. 8084-8106, 2014.

[25] X.-D. Zhang, Q. Wang, P.-F. Li, and R.-Y. Wang, "Research on soil dispersion of Qian'an soil forest," Journal of Northeastern University, vol. 36, no. 11, pp. 1643-1647, 2015.

[26] X. Z. Xu, J. C. Wang, and L. X. Zhang, Physics of Frozen Soils, Science Press, Beijing, China, 2010.

[27] C. Lovell, "Temperature effects on phase composition and strength of partially frozen soil," Highway Research Board Bulletin, vol. 168, pp. 74-95, 1957.

[28] X. Z. Xu, J. L. Oliphant, and A. R. Tice, "Soil-water potential and unfrozen water content and temperature," Journal of Glaciology and Geocryology, vol. 7, no. 1, pp. 1-14, 1985.

[29] X. Zhou, Study on Engineering Property and Unfrozen Water Content Prediction of Saline Soil in Nong'an, Jilin University, Changchun, China, 2006.

[30] Q.-B. Bai, X. Li, Y.-H. Tian, and J.-H. Fang, "Equations and numerical simulation for coupled water and heat transfer in frozen soil," Chinese Journal of Geotechnical Engineering, vol. 37, supplement 2, pp. 131-136, 2015.

[31] D. X. Tang, Y. R. Liu, and W. S. Zhang, Science of Engineering Rock and Soil, Geology Publishing House, Beijing, China, 1999.

[32] X. Y. Lei, "The loess collapsibility and pore types in China," Scientia Sinica (Chimica), vol. 12, pp. 1309-1318, 1987.

[33] Q. Wang and J. P. Wang, "A Study on fractal of porosity in the soils," Chinese Journal of Geotechnical Engineering, vol. 22, no. 4, pp. 496-498, 2000. 


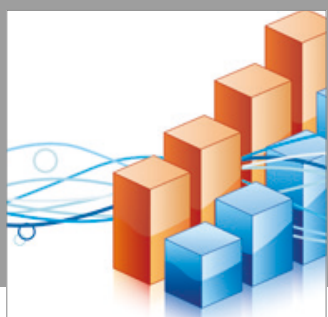

Advances in

Operations Research

vatersals

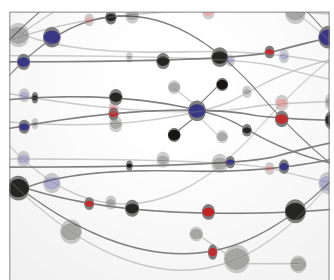

\section{The Scientific} World Journal
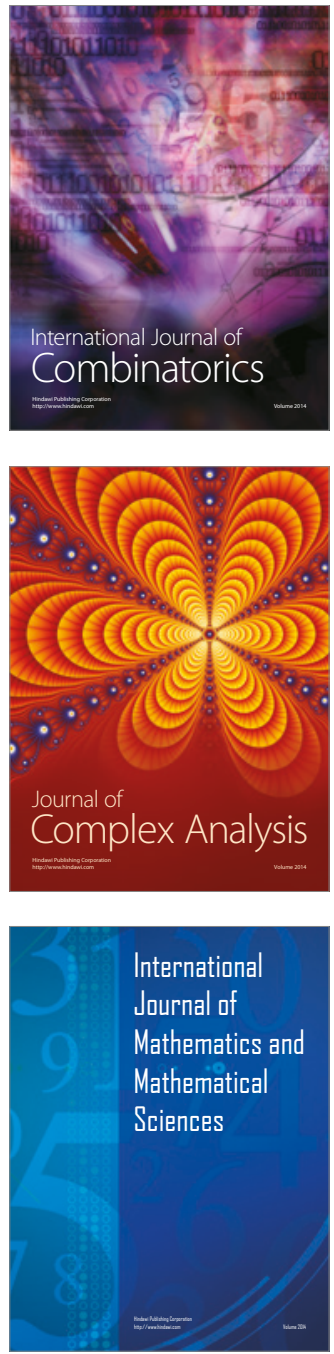
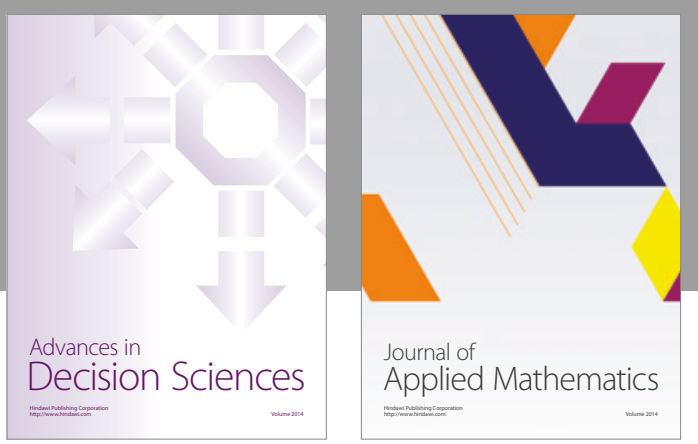

Algebra

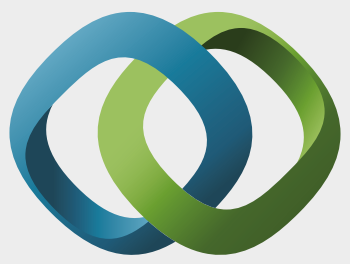

\section{Hindawi}

Submit your manuscripts at

https://www.hindawi.com
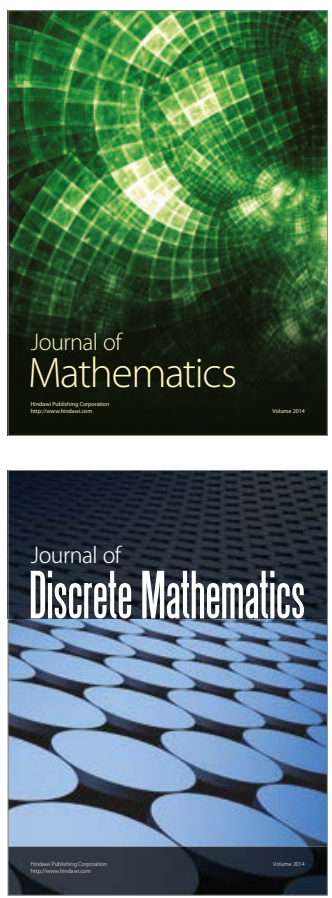

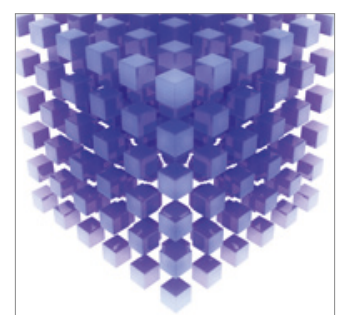

Mathematical Problems in Engineering
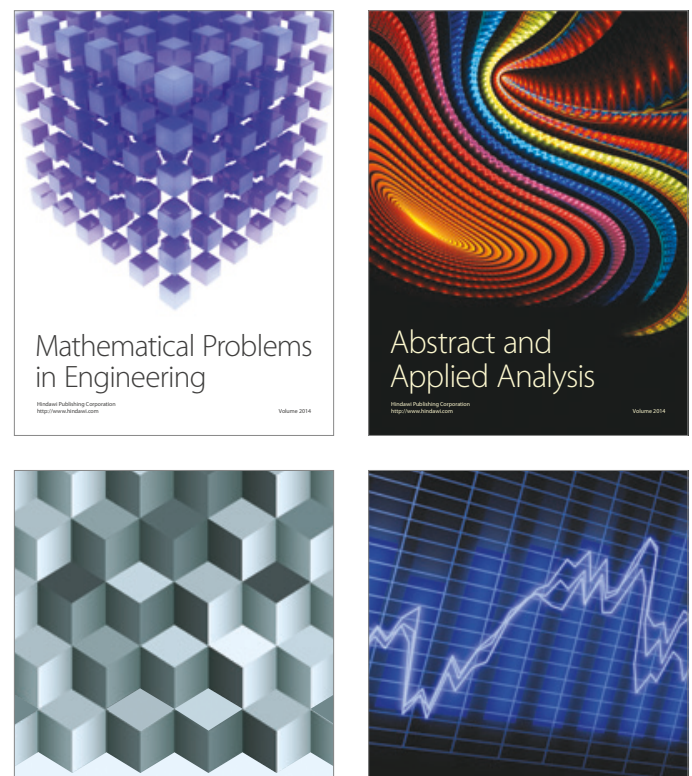

Journal of

Function Spaces

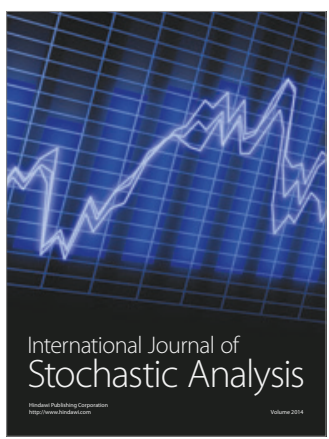

Probability and Statistics
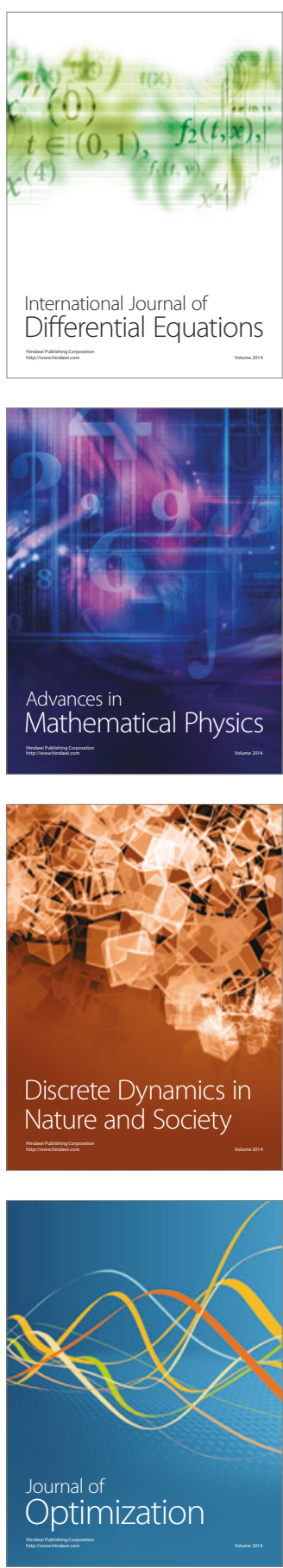